\title{
Deep uncertainty in long-term hurricane risk: scenario generation and implications for future climate experiments
}

\author{
Nicola Ranger and Falk Niehörster \\ July 2011
}

Centre for Climate Change Economics and Policy

Working Paper No. 61

Munich Re Programme Technical Paper No. 8

Grantham Research Institute on Climate Change and the Environment

Working Paper No. 51 
The Centre for Climate Change Economics and Policy (CCCEP) was established by the University of Leeds and the London School of Economics and Political Science in 2008 to advance public and private action on climate change through innovative, rigorous research. The Centre is funded by the UK Economic and Social Research Council and has five inter-linked research programmes:

1. Developing climate science and economics

2. Climate change governance for a new global deal

3. Adaptation to climate change and human development

4. Governments, markets and climate change mitigation

5. The Munich Re Programme - Evaluating the economics of climate risks and opportunities in the insurance sector (funded by Munich Re)

More information about the Centre for Climate Change Economics and Policy can be found at: http://www.cccep.ac.uk.

The Munich Re Programme is evaluating the economics of climate risks and opportunities in the insurance sector. It is a comprehensive research programme that focuses on the assessment of the risks from climate change and on the appropriate responses, to inform decision-making in the private and public sectors. The programme is exploring, from a risk management perspective, the implications of climate change across the world, in terms of both physical impacts and regulatory responses. The programme draws on both science and economics, particularly in interpreting and applying climate and impact information in decision-making for both the short and long term. The programme is also identifying and developing approaches that enable the financial services industries to support effectively climate change adaptation and mitigation, through for example, providing catastrophe insurance against extreme weather events and innovative financial products for carbon markets. This programme is funded by Munich Re and benefits from research collaborations across the industry and public sectors.

The Grantham Research Institute on Climate Change and the Environment was established by the London School of Economics and Political Science in 2008 to bring together international expertise on economics, finance, geography, the environment, international development and political economy to create a worldleading centre for policy-relevant research and training in climate change and the environment. The Institute is funded by the Grantham Foundation for the Protection of the Environment, and has five research programmes:

1. Use of climate science in decision-making

2. Mitigation of climate change (including the roles of carbon markets and lowcarbon technologies)

3. Impacts of, and adaptation to, climate change, and its effects on development

4. Governance of climate change

5. Management of forests and ecosystems

More information about the Grantham Research Institute on Climate Change and the Environment can be found at: http://www.Ise.ac.uk/grantham.

This working paper is intended to stimulate discussion within the research community and among users of research, and its content may have been submitted for publication in academic journals. It has been reviewed by at least one internal referee before publication. The views expressed in this paper represent those of the author(s) and do not necessarily represent those of the host institutions or funders. 


\title{
Deep Uncertainty in Long-term Hurricane Risk: Scenario Generation and Implications for Future Climate Experiments
}

\author{
Nicola Ranger ${ }^{1}$ and Falk Niehörster \\ Centre for Climate Change Economics and Policy \& Grantham Research Institute on Climate Change and the \\ Environment, London School of Economics and Political Science
}

$4^{\text {th }}$ July 2011

\begin{abstract}
Current projections of long-term trends in Atlantic hurricane activity due to climate change are deeply uncertain, both in magnitude and sign. This creates challenges for adaptation planning in exposed coastal communities. We present a framework to support the interpretation of current long-term tropical cyclone projections, which accommodates the nature of the uncertainty and aims to facilitate robust decision making using the information that is available today. The framework is populated with projections taken from the recent literature to develop a set of scenarios of long-term hurricane hazard. Hazard scenarios are then used to generate risk scenarios for Florida using a coupled climate-catastrophe modeling approach. The scenarios represent a broad range of plausible futures; from wind-related hurricane losses in Florida halving by the end of the century to more than a four-fold increase due to climate change alone. We suggest that it is not possible, based on current evidence, to meaningfully quantify the relative confidence of each scenario. The analyses also suggest that natural variability is likely to be the dominant driver of the level and volatility of wind-related risk over the coming decade; however, under the highest scenario, the superposition of this natural variability and anthropogenic climate change could mean notably increased levels of risk within the decade. Finally, we present a series of analyses to better understand the relative adequacy of the different models that underpin the scenarios and draw conclusions for the design of future climate science and modeling experiments to be most informative for adaptation.
\end{abstract}

\section{Introduction}

\footnotetext{
${ }^{1}$ Corresponding author: Houghton Street, London, WC2A 2AE; email: n.ranger@1se.ac.uk.
} 
Damages related to tropical cyclones on the US Atlantic and Gulf coasts have spiraled upwards over the past few decades as populations and assets have become increasingly concentrated in exposed coastal regions (e.g. Pielke and Landsea 1998). There is insufficient evidence to confirm whether or not anthropogenic climate change (hereafter, referred to as climate change) has contributed to the increase in past damages (e.g. Neumayer and Bartel, 2010). But there are indications that climate change may exacerbate hurricane risk in the future. There is an urgent need to consider future hurricane risk in long-term planning and policy decisions, for example, over how and where new properties and infrastructure are developed, as decisions made today that are appropriate to current climate could lock-in substantial future exposure and vulnerability in a changed climate. The challenge for decision makers is that the future characteristics of tropical cyclone hazards are uncertain, particularly at a regional level.

Knutson et al. 2010 reviewed current evidence and concluded that globally, climate change is likely to lead to either a reduced, or essentially unchanged, tropical cyclone frequency, alongside an increase in average maximum wind speeds. There is lower consensus over projections for individual ocean basins. For the Atlantic Basin, of the twelve studies reviewed by Knutson et al. 2010, around one third predict an increase in frequency and two-thirds a decrease. Studies concerning the intensity of tropical cyclones are more challenged by the resolution of current global climate models, so called general circulation models (GCMs), which is not yet sufficient to simulate the most intense storms (Emanuel 2008). The majority of the studies reviewed by Knutson et al. project, on average, an increase in storm intensity in the Atlantic Basin, although a minority of individual GCMs used in these studies do project reductions (where different studies use alternate metrics, including the frequency of the most intense storms, the potential intensity or maximum wind speeds). Many other characteristics relevant to risk estimation are even more uncertain; for example, changes in the distribution of tropical storm tracks, genesis locations, speeds, sizes and landfall locations. Knutson et al. reported that few studies have explored the affects of climate change on these characteristics and there is little consensus in projections.

While it is important to continue to refine projections, some types of adaptation decisions can not be delayed until there is greater certainty in long-term hurricane prediction; for example, greater certainty in projections could take more than a decade to achieve (e.g. Zickfield et al. 2010) and meanwhile infrastructure and development planning decisions made today will affect risk levels for many decades to come. This paper seeks to provide an informative set of scenarios of wind-driven hurricane risk based on peer-reviewed science and modeling available today. This paper is only a first step towards an informative set of scenarios; firstly, 
it does not address all uncertainties, only those related to the future frequency and intensity of tropical storms in the Atlantic Basin, and secondly, the scenario set will be refined over time as new information becomes available. The following two sections describe the framework and methodologies used for generating the scenarios. Sections 4and 5 analyze the hazard and risk scenarios.

Scenarios of future states have long been used in the management of natural hazards, as well as decision-making more broadly. Van der Heijden (2005) suggests that such scenarios can serve as a "test-bed for policies and plans" as well as guiding future research to refine projections. Section 6 will briefly discuss the first of these applications, how the scenarios can be used to inform adaptation planning; though most focus in the discussion will be placed on the second application, using the scenarios to consider how future climate science and modeling experiments could be best designed to be most informative for adaptation.

\section{The Framework}

A scenario is a description of a possible future state; in this case, a possible future tropical cyclone climate. Appropriate model selection is crucial in generating a set of scenarios to inform decision making. Groves and Lempert (2006) and van der Heijden (2005) suggest that a set of scenarios should aim to explore all the most significant driving forces affecting future risks and decisions and be representative of the range of possible future outcomes. Several other authors have also noted the importance of including extreme scenarios in decision analysis (Parson 2008; Groves et al. 2007a; Hallegatte 2009; Morgan 2003) and this was an important lesson learnt from the Thames Estuary 2100 project in the UK, which used a scenario-based approach to design a new tidal flood protection system for London for the $21^{\text {st }}$ century (Lowe et al. 2009).

For these reasons, the framework aims to select models to represent the widest possible range of plausible future states for the key determinants of future wind-related risk. A condition imposed on this range, after Lempert et al. 2003, is that the scenarios are scientifically plausible and rigorous; which we define as being based on modeling and approaches that are grounded in scientific theory and published in the peer-reviewed literature.

Van der Heijden (2005) suggests that a framework for developing scenarios can be derived from identifying key events or stages of uncertainty that will drive the scenario progression. Scenarios can then be developed that systematically explore the range of consequences of these events or stages. We suggest there are three major stages of uncertainty in projections of long-term tropical cyclone activity in the Atlantic Basin (after Jones 2000). The first (I) is the 
emissions scenario uncertainty; this is discussed in Section 3. The second (II) is uncertainty in the response of the large-scale (global to ocean basin-scale) climate and ocean environment to manmade emissions. In current projections, this uncertainty stems from missing processes and the parameterization of processes in global climate models (McAvaney et al. 2001, Randall et al. 2007). The third stage (III) is the uncertainty in the link between the ocean basin-scale environment and basin tropical cyclone activity. We distinguish the second and third stages because these are generally treated by different models; computational constraints mean that the resolution of global models (even of the highest-resolution models available) is insufficient to simulate all the processes involved in tropical cyclone development and for this reason downscaling models are used to project changes in regional tropical cyclone characteristics for a given large-scale environment. These downscaling models add an additional layer of uncertainty (Emanuel 2008, Maraun et al. 2010).

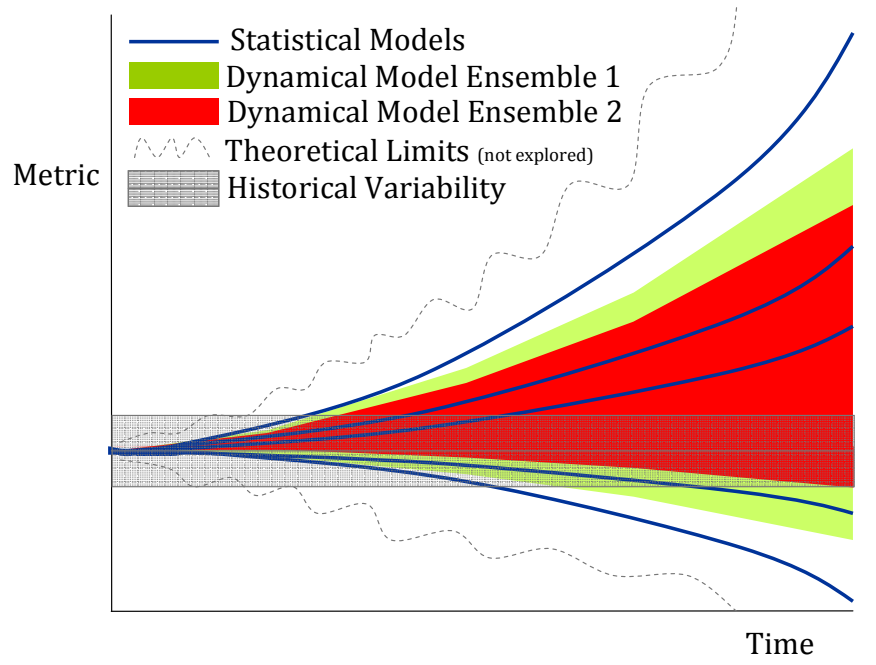

Figure 1: Schematic diagram illustrating the framework for scenario generation. The grey wavy lines signify that it is not possible to exclude scenarios outside of the ranges indicated by the scenarios. In reality, the evolution of the metric is unlikely to be a smooth progression as suggested by this diagram.

The scenarios available in the recent scientific literature generally fall into two types that roughly reflect the van der Heijden (2005) framework. The first type utilizes a range of projections of the large-scale environment sourced from multiple GCMs (i.e. the stage II uncertainty), but only a single representation of the link to basin tropical cyclone activity (stage III), typically using a dynamical downscaling model; that is, a higher-resolution regional model that simulates the tropical cyclone climatology conditioned on a particular GCM projection. These scenarios are denoted "Dynamical Model" scenarios. The second type also uses a range of GCM projections, but explores a broader range of the uncertainty in the link to basin tropical cyclone activity (stage III); typically using simpler downscaling 
approaches. For example, Vecchi et al. 2008 presents a set of simple models which utilize statistical downscaling techniques (based on only one or two predictors) coupled with a range of GCM projections. These scenarios are denoted "Statistical Model" scenarios. Few studies explore more than one emissions scenario.

In this study, we utilize both of these types of scenarios. The Dynamical Model scenarios represent the 'state-of-the-art' in current long-term prediction. These are complemented by the Statistical Model scenarios, which have the advantage of representing a broader range of the uncertainty. While the models underlying the Statistical Model scenarios are simpler than those used by the Dynamical Model scenarios there is evidence that they provide adequate predictions of basin-scale tropical cyclone frequency and intensity over the near- and longterm (Emanuel, 2005, Hoyos et al. 2006). They also have the advantage of being directly driven by large-scale climate variables (such as basin-scale sea surface temperatures) in which one can have greater confidence than in the grid-scale variables used by the dynamical downscaling approaches.

For decision support, it is important to recognize that the upper and lower bounds on future risk suggested by the range of scenarios generated here are not the true limits to the space of all plausible future states. For example, while the Statistical Models could be interpreted as capturing the bounds of plausible changes in hurricane activity given a specific large-scale climate projection (the stage III uncertainty), the GCMs on which these projections are based represent only a lower-bound on the true range of (the stage II) uncertainty (e.g. Oreskes $e$ al. 2010; Stainforth et al. 2007a,b; Morgan 2003). For example, Knutti et al. 2010 describes that current GCMs share many common structures and attributes, which means they are not independent and provide only a limited sampling of the uncertainties in the models. The level of confidence in the range of future states suggested by the scenario set decreases with both prediction lead time (e.g. Cox and Stephenson, 2007; Hawkins and Sutton, 2009) and the deviation of predicted variable from its current level because the GCMs as well as the downscaling models are tuned towards the present-day climate.

In this study, the breadth of the scenario set is constrained by the condition that modeling and approaches are grounded in scientific theory and published in the peer-reviewed literature. Our constraint is supported by Lempert et al. 2003, which suggests that an ensemble of scenarios should aim to "provide the greatest possible diversity of plausible futures consistent with available information". Transparency about the nature of the uncertainties is essential for decision support as this can enable a decision maker to select an appropriate interpretation of the scenarios; for example, where the scenario set is less well constrained, she may opt for 
a more robust strategy. Parson 2008 and IPCC 2005 suggest that the types of information that are important to provide are the sources of uncertainty in scenario generation and the drivers that could mean that in reality the future state is outside of the range suggested by the set.

Finally, the scenarios aim to represent only the component of annual changes in risk driven by climate change. Another important driver of risk and uncertainty, particularly over short timescales, is natural variability. The annual average frequency and intensity of tropical cyclones in the Atlantic Basin is highly (naturally) variable on annual, multi-annual and decadal timescales, driven by chaotic weather processes and natural cycles (Goldenberg et al. 2001). In this study, projections are presented as 5-year average time slices. This averaging removes annual variability in hazard and risk levels but does not remove decadal variability. The amplitude of decadal variability simulated in GCMs tends to be smaller than is observed (e.g. Gillet et al. 2008) and this means that decadal variability should be considered in addition to the climate change trends presented in this research. The implications of this are discussed in Section 4.

The amplitude of natural variability on a decadal to multi-decadal time scale, which historically has been associated with significant shifts in the level of damages experienced by coastal communities around the Atlantic, provides a useful benchmark against which to assess the scale of climate change. In this study, the range of natural variability is represented as the difference between the observed activity levels in recent active and inactive periods (defined as 1995-2010 and 1972-1994, respectively) based on data from the HURDAT database (Landsea et al. 2004).

\subsection{Identifying "Decision-Relevant” Metrics}

The design of a scenario set can not be independent of its application. To guide scenario design, this study takes the illustrative case of an evaluation of residential property development policies in Florida to protect against wind-related hurricane damage; a case of a long-lived decision with high sunk-costs. Given that residential properties are most vulnerable to intense hurricanes (e.g. ARA 2008), the decision will be highly sensitive to changes in the frequency of intense (above Category 3 on the Saffir Simpson scale) hurricanes affecting Florida and, to a lesser extent, the frequency of all named storms (Category 0 to 3 ) over the next century. For this reason, we develop scenarios for these two metrics (labeled CAT45 and NAMEST, respectively), which could be considered proxies for the intensity and frequency of storms, respectively. Given the nature of the uncertainties in long-term hurricane projections, these aggregated metrics are considered a more robust starting point for adaptation planning than a more detailed metric, such as time-dependent wind-speed frequency distributions. 
Other tropical cyclone metrics, such as storm size and the distribution of landfalls, are relevant for this adaptation problem, but the level of confidence in projections for these metrics is currently very low (Knutson et al. 2010). For this reason, we assume that these metrics retain their climatological distributions. Given that it is known that these factors can affect losses at a local scale, it would be beneficial to test the sensitivity of any adaptation appraisal to the assumptions made using appropriate sets of plausible scenarios. This is beyond the scope of the present study.

\section{Methodology for Generating Basin-Level Hazard Scenarios}

In this section, hazard scenarios are generated at Atlantic basin-scale. In all cases the projections available in the peer-reviewed literature require some reprocessing, or in some cases regeneration, to develop a set of scenarios with consistent baselines, emissions scenarios, timescales and metrics, such that they are comparable and compatible within the framework.

Each scenario is represented as relative to the observed $1990(1981-1999)$ baseline. It is to be noted that the 1990 baseline level of hurricane activity (both intensity and frequency) is significantly lower than the level observed over the past fifteen years, which has been generally regarded as an 'active' period in hurricane activity (supplementary materials $C^{2}$ ).

Projections are produced for three 5-year time-slices centered around the years 2020, 2040 and 2090. The chosen time-slices reflect the information needs for long-term adaptation planning (i.e. adapting residential properties) as well as requirements for shorter-term applications, such as insurance and disaster preparedness. Each scenario is based on the SRES A1B emissions scenario (Nakicenovic and Swart, 2000). We find that one emissions scenario is adequate in this case as the sensitivity of predictor variables (such as tropical Atlantic sea surface temperature, SST) to the emissions scenario uncertainty is low (supplementary materials B).

\subsection{Dynamical Model Scenarios}

Projections are taken from two recent studies, Emanuel et al. 2008 and Bender et al. 2010 (hereafter, E2008 and B2010, respectively). These were selected as they are the first to provide long-term projections for the Atlantic Basin that explicitly simulate adjustments in the frequencies of Category 4 and 5 storms; each study applies a different dynamical downscaling

\footnotetext{
${ }^{2}$ Supplementary materials are available on request to the corresponding author.
} 
approach (i.e. high resolution models one-way nested into a GCM) to simulate hurricane activity using projections of the large-scale climate simulated by GCMs. Together the two studies use individual projections from nine different GCMs (with two GCMs used in both studies: MRI CGCM2.3.2a and MPI ECHAM5). B2010 also produces an Ensemble projection of the large-scale climate from eighteen GCMs from the World Climate Research Program Coupled Model Intercomparison Project 3 (CMIP3).

The B2010 projections for 2081-2100 are linearly interpolated to provide the 5-year-average time-slice data for 2020, 2040 and 2090. The assumption of a linear change may lead to a slight overestimation of near-term changes, however this is small (for example, $\leq 1 \%$ in 2020 for all but one model and $<3 \%$ in all cases when compared with an interpolation using a constant growth rate) and there is no evidence to support any alternative assumption. The projections from E2008 were reprocessed to give the CAT45 and NAMEST metrics (Kerry Emanuel, pers. comm.) and similarly interpolated to produce the time-slice data.

\subsection{Statistical Model Scenarios}

Following approaches defined in the peer-reviewed literature (Vecchi and Soden 2007a, Vecchi et al. 2008, Saunders and Lee, 2008), the 'Statistical Models' are based on a linear regression technique that aims to capture the statistical relationship between the metrics (CAT45 and NAMEST) and one or more large-scale climate 'predictors' (on a 5-year average basis over the hurricane season). This relationship is then used to produce a future projection of hurricane activity based on GCM projections of the predictor variables. Different statistical models represent different (combinations of) large-scale predictors and are designed such that they are grounded in scientific theory on the drivers of tropical cyclone activity.

In this study, the statistical relationships between the predictors and hurricane activity are derived from reanalysis data (ERA40, Uppala et al. 2005) and the HURDAT database. The approach, model parameters and regression results are outlined in the supplementary materials A. Four sets of predictors are used, reflecting those shown in the peer-reviewed literature to have a strong correlation with Atlantic hurricane activity and/or an empirical or theoretical causal relationship:

1. MDR-SST: the SST in the Atlantic Main Development Region (MDR) (Saunders and Lee, 2008; Vecchi et al. 2008);

2. REL-SST: the relative SST of the MDR to the tropical mean SST (Vecchi et al. 2008);

3. WNDSHR: the local vertical windshear in the MDR (Saunders and Lee, 2008); 
4. MDR-SST + WNDSHR: a bi-variate model including both MDR SST and MDR windshear (Saunders and Lee, 2008).

The correlation coefficient $\left(\mathrm{r}^{2}\right.$ value) for the statistical models ranges from 0.44 to 0.69 , with the models including MDR-SST giving the highest correlation for NAMEST (0.66 and 0.69) and the two models including WNDSHR giving the highest correlation for CAT45 (0.65 and 0.68). These coefficients do not however imply a level of relative confidence of the scenario; while linear correlation values give an insight into whether a predictand is linearly related to a set of predictors, it does not necessarily itself indicate a causal relationship.

A commonly-used large-scale predictor that is missing from this set is the "Maximum Potential Intensity" (MPI) (Emanuel 1987). MPI is not included in this study due to the fact that available time series of past MPI are judged to be unreliable and too short to adequately train a regression model (supplementary materials $A$ ).

Future scenarios are derived by applying the regression models to projections of the relevant predictors taken from a GCM (i.e. statistical downscaling). An ensemble of projections is derived from the 21 GCMs of CMIP3 for each predictor, leading to 21 individual Statistical Model projections for each of the four Models and two metrics (supplementary materials A). This set of GCMs is larger than those represented by the Dynamical Model scenarios. In this paper, we present as scenarios only the ensemble mean and \pm 1 standard deviation projections across the set of 21 projections.

The set of scenarios developed in this study (a total of 24 scenarios; 12 Dynamical Model scenarios and 12 Statistical Model scenarios) is much larger than is suggested to be optimal for scenario-based planning approaches (e.g. around 4, suggested by van der Heijden, 2005). In this study, we maintain the large number of scenarios so that they can also be informative for planning for climate experiments; that is, with the larger set, the key drivers of uncertainty remain clear and one can identify where uncertainties can be narrowed to greatest benefit.

\section{Analysis of Hazard Scenarios}

Figure 2 summarizes the temporal evolution of the hazard scenarios for the two target metrics, CAT45 (y-axis) and NAMEST (x-axis). Each scenario is plotted relative to the baseline level. The scenarios radiate out from their shared baseline value (represented by 1.0/1.0 on Figure 2). The differences in the evolution of the scenarios against the two dimensions are quite stark. The majority of scenarios show either little change or a reduction in the total number of named storms in the Atlantic Basin. The findings are more mixed for the number of intense storms; nine out of the twelve Dynamical Model scenarios show an increase in the number of 
intense storms and only one of the Statistical Models (MDR-SST). Overall, the scenario set appears to cover the range of projections from the broader set of studies reviewed by Knutson et al. 2010 (though it is difficult to make direct comparisons given the variety of metrics used in previous studies).

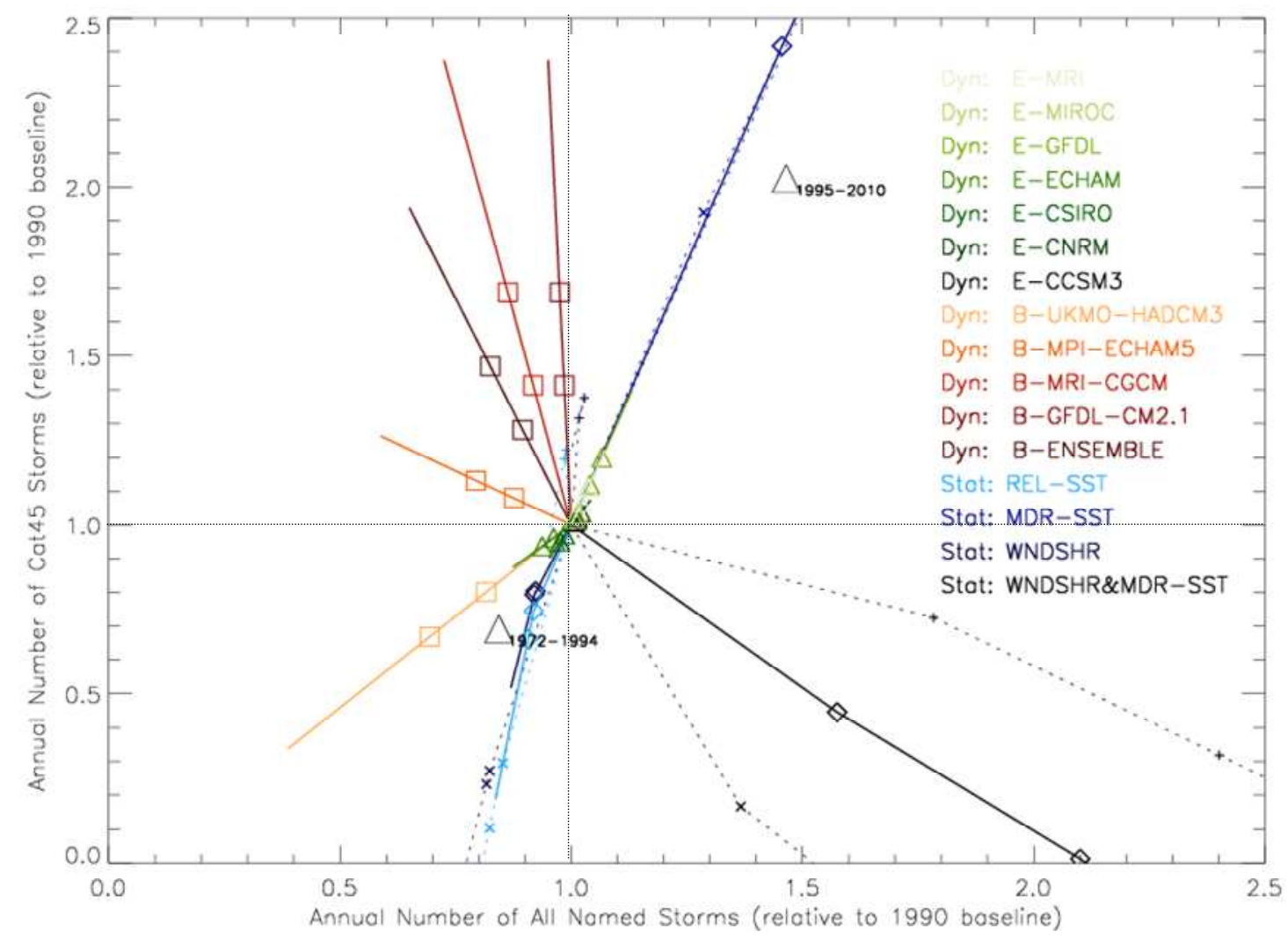

Figure 2: Projected changes in hurricane activity rates for all scenarios plotted against the two target metrics, NAMEST on x-axis and CAT45 on y-axis, shown relative to the 1990 baseline level. All projections start at the baseline (at 1,1) and evolve to the 2090 estimate, with the squares or triangles marking the 2020 and 2040 projections. The set of hazard scenarios include the Dynamical Model scenarios (from E2008 in shades of green and B2010 in shades of red) and the Statistical Model scenarios (in shades of blue). Scenarios representing the mean \pm 1 standard deviation predictions from the statistical models are indicated by the dotted line (crosses mark the projections in 2020 and 2040); note that these are not visible on the Model MDR SST because they are aligned with the mean projection. The two black triangles show the levels during the recent 'active period' (1995-2010) and the levels during the earlier 'inactive period' (1972-1994). A larger version of this figure, showing the complete space of projections, is included in the supplementary materials $D$.

The MDR-SST and WNDSHR/REL-SST scenarios produce almost diametrically opposite changes in both metrics and have similar characteristics (in terms of the direction of changes in CAT45 and NAMEST) to historical active and inactive periods, respectively (Figure 2). This difference in projections of these two sets of statistical models is not unexpected as in reality these drivers of tropical cyclone activity moderate one another (Vecchi and Soden, 2007b). The Dynamical Model scenarios appear as a blending between these two extremes, with some scenarios taking on more MDR-SST like characteristics (e.g. GFDL-CM2.1 from 
B2010 and GFDL, CCSM3, CNRM, MIROC and MRI from E2008) and others more towards WNDSHR/REL SST (e.g. UKMO-HADCM3 from B2010 and CSIRO and ECHAM from E2008). The combined Statistical Model scenario, WNDSHR\&MDR-SST, in contrast to the other scenarios and historical variability, projects a rapid decline in the number of intense hurricanes but increase in the number of named storms (see supplementary material A for a discussion).

Figure 3 gives the absolute values of the scenarios. In general, scenarios based on B2010 give larger changes in the number of intense storms than those based on E2008. Scenarios based on E2008 also tend to predict small increases in the frequency of all named storms, while those based on B2010 tend to predict small reductions, even for the same GCMs (n.b. the following GCMs are the same in both studies: MRI CGCM2.3.2a = MRI and MPI ECHAM5 $=$ ECHAM in Figure 3; however, we retain the original naming from B2010 and E2008 to facilitate comparison to those studies). This suggests that it is the downscaling approaches of the two studies that drive the differences in projections. One explanation for the differences could be related to the use of an upper-ocean thermal structure from a present-day climatology in E2008.

Analysis of the scenario set suggests that natural variability could remain the dominant driver of risk for at least a decade, and much longer in some cases. For example, Figure 3 demonstrates that only the most extreme Dynamical Model scenario (UKMO-HadCM3) and the four most extreme Statistical Model scenarios (i.e. a total of five out of 24 scenarios) move outside of the range of observed natural variability in the number of named storms in the Basin in 2020 and by 2090 just over half of all scenarios have moved outside of this range. For the CAT45 metric, six of the Statistical Model scenarios move outside of the range of natural variability by 2020 but none of the Dynamical Model scenarios. By 2090, still only the three most extreme Dynamical Model scenarios (UKMO-HadCM3, GFDL.CM2.1 and MRI-CGCM) move outside of the range of natural variability. This is consistent with the findings of B2010, which concluded that due to natural variability it will be impossible to detect a robust signal of changes in the most intense hurricanes in meteorological observations until the second-half of the twenty-first century (and longer for an observable signal in loss records, Crompton et al. 2011). This does not mean that climate change will have no effect on risk levels in the coming decade. Natural variability will be superimposed onto any anthropogenic trend of increasing or decreasing mean risk levels. It is not known whether this superposition will be linear and how climate change will impact natural variability itself. It is clear that we can not exclude the possibility of experiencing risk levels outside of the historical range of natural variability; for example, under the MDR_SST 
scenario, a linear superposition would imply that active periods could become more active than seen before within the decade.

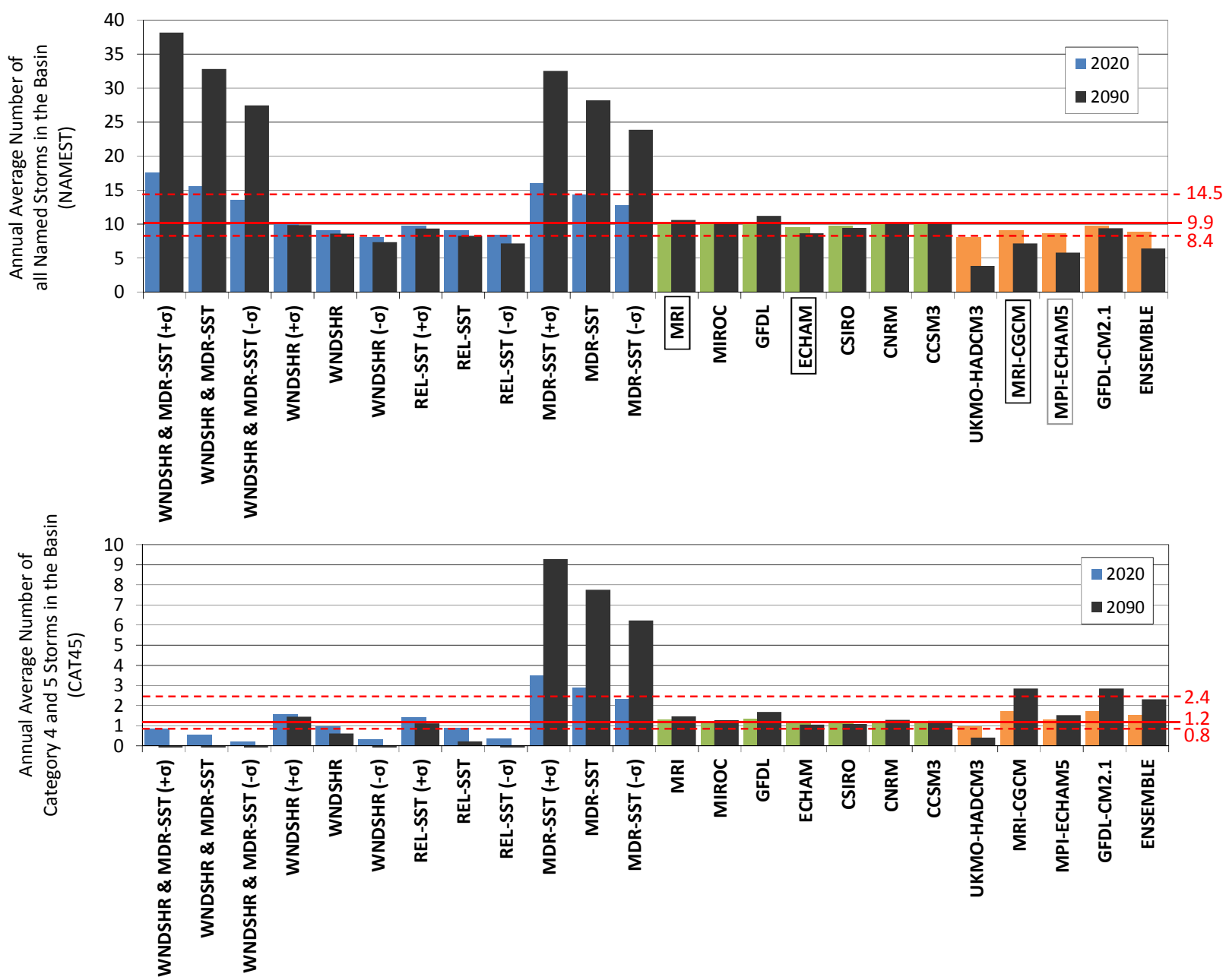

Figure 3: The hazard scenarios: projections of the average annual number of all named storms in the Basin (NAMEST, top) and projections of the average annual number all Category 4 and 5 storms in the Basin (CAT45, bottom). The blue bars are the Statistical Model scenarios for 2020 and the green and orange bars are the Dynamical Model scenarios for 2020 from E2008 and B2010, respectively. Three scenarios are shown for each Statistical Model; these are projections based on the ensemble mean of the 21 individual GCMs and the \pm 1 standard deviation. The dark shaded bars are the equivalent projections for 2090. The red lines show benchmark points: the solid line is the 1990 baseline level and the two dashed lines are the average rates over the recent active (defined as 1995-2010) and inactive (defined as 1972-1994) periods. Identical GCMs between E2008 and B2010 are indicated with boxes.

\subsection{Model adequacy and relative confidence}

Given the broad range of projections implied by the scenarios it is useful to consider whether one or more of these scenarios could be excluded, or given a lower degree of confidence, on the basis of arguments about model adequacy. There is no one metric of model adequacy (Knutti et al. 2010). The fact that Dynamical Model scenarios are close together relative to 
the Statistical Models can not be interpreted as a measure of confidence, as in many cases the models on which that Dynamical Model scenarios are based will share similar assumptions (Knutti et al. 2010).

Each of the models drawn upon in this study has been shown to represent present-day variability in tropical cyclone activity in the Atlantic Basin, to varying degrees (E2008; B2010; Vecchi et al. 2008, Saunders and Lee, 2008). While the ability of a model to represent the past is also not a guarantee of a model's ability to represent the future; it is a useful starting point. Given that future trends due to climate change will be mainly driven by changes in the large-scale climate environment, another useful metric might be the ability of the GCM to adequately represent the present-day relationships between the large-scale climate drivers. Figure 4 shows the predicted MDR windshear and SST anomalies from each of the GCMs of the CMIP3 ensemble, averaged over the 2040 and 2090 5-year time slices. All models predict an increase in MDR SSTs (to varying degrees), but there is little consensus in either the scale or direction of changes in MDR windshear (supplementary materials A, Figure S.1). The GCMs used in the B2010 and E2008 studies are highlighted. Comparing predictions from these models to those in Figure 3, some relationships emerge (the model set is too small to draw strong conclusions). We suggest that differences in predictions of future windshear are an important cause of the diversity in tropical cyclone projections shown in Figure 3. Those GCMs that predict the largest increases in windshear alongside increases in MDR SSTs (CSIRO MK3.0 and UKMO-HadCM3) tend to lead to predictions of a decreasing number of named storms and category 4-5 storms. Those models that predict either little change in windshear or a large decrease (such as GFDL-CM2.0) tend to predict increases in the number of category 4-5 storms and little change (or in one case a large increase) in the total number of named storms (where the sign of the change depends on the downscaling approach). 


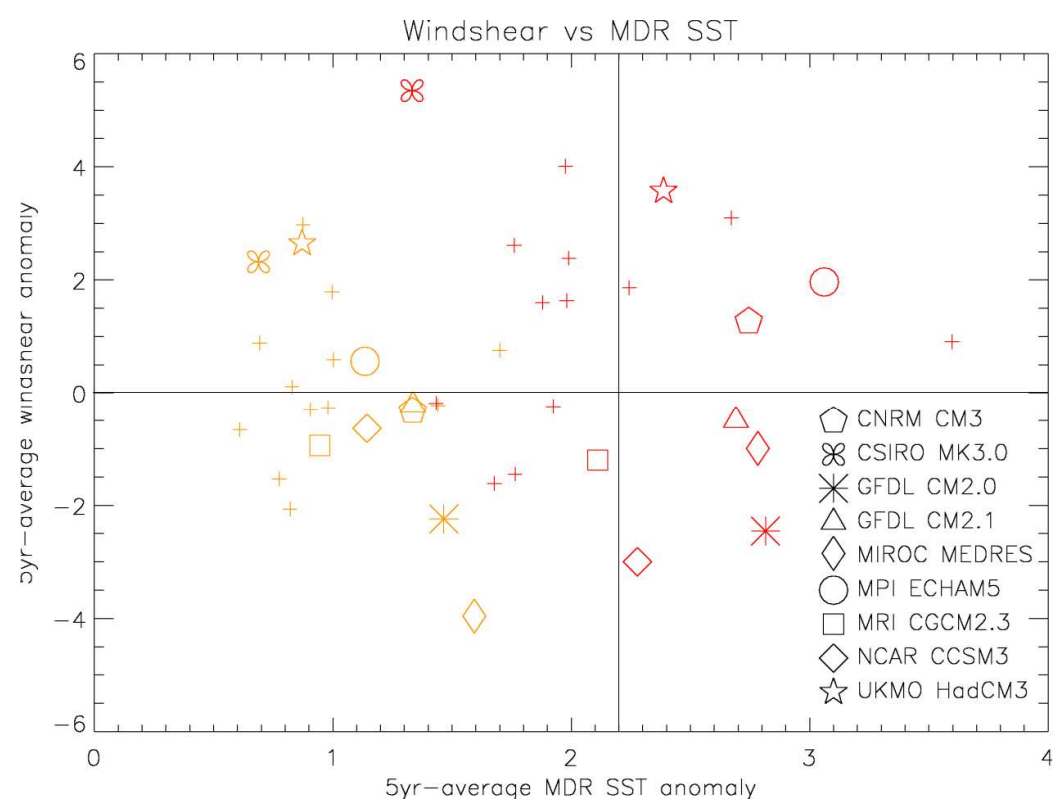

Figure 4: The relationship between 5-year average windshear and sea surface temperature (SST) in the Atlantic main development region (MDR) for CMIP3 ensemble, for 2040 (orange) and 2090 (red). The GCMs used in B2010 and E2008 are highlighted as indicated in the legend; all other models are indicated by a cross.

Given the apparent importance of long-term projections of windshear, an important indicator of model adequacy could be the ability of models to represent the relationship between windshear and MDR-SST in the past. In agreement with previous studies (e.g. Gillet et al. 2008), we find that the relationship between these variables is far weaker in all of the GCMs than is suggested by the ERA-40 reanalysis data (supplementary materials E). The absolute values of these two variables over the baseline period are also inconsistent with the reanalyzes of past data and demonstrate substantial model biases. No group of GCMs appears to perform particularly well or poorly in these respects. This difference from the observations might lead one to question the adequacy of these models for prediction.

It should be noted that there is uncertainty in the appropriate baseline value from which anomalies are calculated that could imply a systematic bias in each of the scenarios. Some authors (e.g. Elsner 2006; Gillet et al. 2008; Holland and Webster, 2007; Mann and Emanuel, 2006; Trenberth and Shea 2006; Santer et al. 2006; Smith et al. 2010) suggest that climate change has already impacted hurricane activity. If this were the case, it could mean that the 1981-1999 period was actually an inactive period, rather than a neutral period; a simple thought experiment (i.e. making the simplistic assumption that climate change were represented by the simple linear trend on observed tropical cyclone data since 1950, supplementary materials $C$ ) suggests negative biases on the absolute values of the scenarios of up to around 1.5 for all named storms (+15\% of the 1990 baseline) and 0.3 for category $4-5$ storms ( $+21 \%$ of the 1990 baseline) in the 5 -year average time slices. This uncertainty leads 
to an additional uncertainty in estimates of the expected losses derived from the hazard scenarios. Better understanding the role of natural cycles in past Atlantic tropical cyclone activity (and therefore, the role of climate change) would help to resolve this uncertainty in the baseline, lead to improved estimates of current and future risk, and could allow the exclusion of some of the scenarios if they were found to be inconsistent with observed trends.

\section{Risk Scenarios for Wind-Related Property Damage in Florida}

A simplified risk model is applied to estimate the implications of the scenario set for windrelated residential property losses in Florida. The risk metrics derived in this paper are the average annual loss (AAL), the standard deviation of loss and the exceedence probability curve (Grossi and Kunreuther, 2005). The core risk model is based on proprietary probabilityloss data provided by Risk Management Solutions Inc. and represents the long-term average (defined as 1950 - 2005) level of risk for a large portfolio of current residential properties in Florida. The model is a simplification of a full catastrophe model: losses are aggregated to state level; and secondary uncertainties from, for example, the uncertain vulnerability of properties, are not captured. The climate change scenarios are each applied deterministically by adjusting the frequencies of individual events within the risk model based on the two metrics. Exposure and vulnerability is held constant over time. The detailed methodologies are described in supplementary materials $F$.

Figure 5 shows the estimated AAL relative to the baseline (1981-1990) level for each of the climate change scenarios in 2020 and 2090, where the baseline AAL for this portfolio is estimated to be around \$3.6 billion USD. In all but one of the Dynamical Model scenarios the AAL remains roughly constant (to within 3 per cent) or increases up to twenty percent in 2020. By 2090, the divergence increases, with the most significant increases predicted by the scenarios based on GFDL-CM2.1, GFDL and MRI-CGCM. The only Dynamical Model scenario with a significant decrease in AAL in both 2020 and 2090 is the scenario based on UKMO-HADCM3, which suggests more than a halving of AAL by 2090. The most significant increases in AAL are suggested by the two sets of Statistical Model scenarios that incorporate MDR-SST; the pure MDR-SST scenario suggests more than a four-fold increase in AAL by 2090. The WNDSHR and REL-SST models suggest a reduction in AAL similar in magnitude to UKMO-HADCM3. As discussed in Section 4, these predictions of negative changes appear to be contingent on experiencing significant increases in windshear in the tropical Atlantic due to climate change.

Comparing Figure 5 with Figure 2 leads to the conclusion that changes in the intensity and frequency of tropical cyclones are both important determinants of future AAL. For example, 
for the Statistical Model scenarios based on the WNDSHR\&MDR-SST model, strong increases in the number of named storms appears to offset the strong reduction in the number of Category 4 and 5 storms, leading to an increase in AAL in most cases, whereas for the Dynamical Model scenarios based on B2010, strong increases in the Category 4 and 5 storms (if large enough) can offset a moderate reduction in the number of named storms to give an increase in risk.

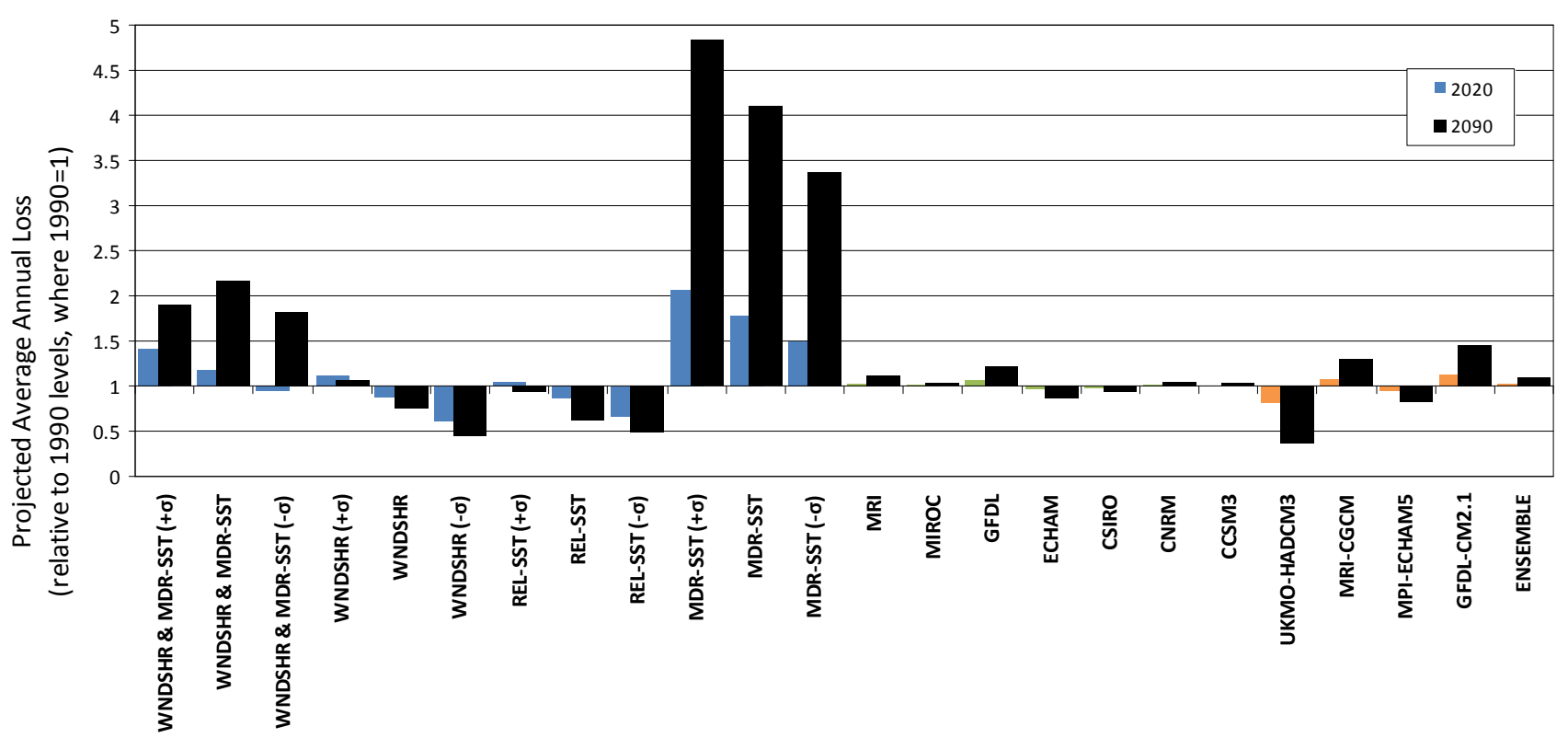

Figure 5: The projected AAL, expressed as a ratio relative to the 1990 baseline, for each of the scenarios in 2020 (colored bars) and 2090 (black bars). The blue bars for 2020 are the Statistical Model scenarios and the green and orange bars are the Dynamical Model scenarios from E2008 and B2010, respectively.

Increases in average risk tend to be accompanied by increases in the volatility of risk (and vice versa), as represented by the standard deviation of loss for each scenario (supplementary materials $F$ ). Figure 6 gives exceedance probability curves for each scenario in 2020. This suggests that even in 2020 there could be significant changes in the probabilities of multibillion USD losses, even though changes in the AAL are more moderate. Such a large loss would be caused by a Category 4 or 5 hurricane striking a densely populated area, but because the probability of such an event is low it has a relatively small effect on the AAL. A narrowing of uncertainties in projections of the intensity of tropical cyclones would be valuable for disaster preparedness and insurance systems in Florida, which need to prepare for such events. 


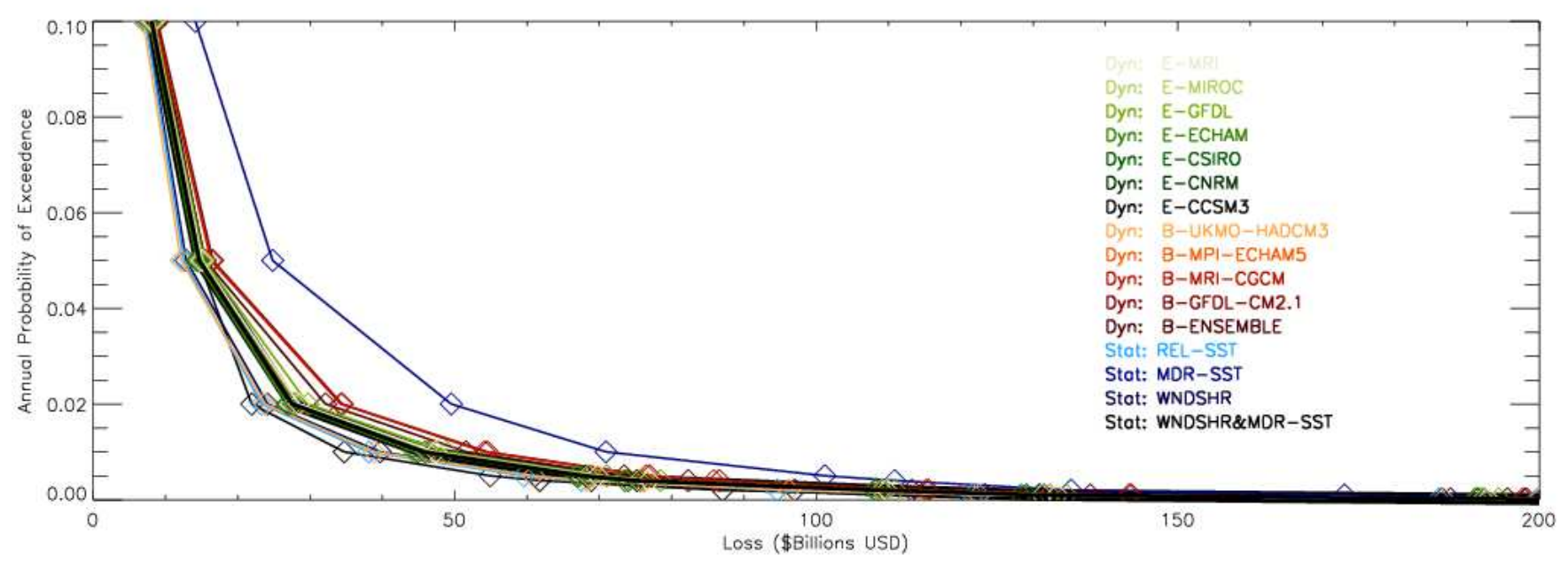

Figure 6: The estimated exceedence probability curves for each scenario in 2020. The thick black line represents the long-term average level. For simplicity, only the Dynamical Model scenarios and ensemble mean Statistical Model scenarios are shown.

\section{Discussion}

The analysis presented in Section 4 suggests that it is not possible to draw conclusions about the relative confidence of the Dynamical and Statistical Model scenarios as both are conditioned on the same set of GCM projections and there is no evidence that one group of GCMs or downscaling approaches is more adequate than the other. This leads us to the conclusion that the nature of the uncertainty in long-term risks from Atlantic tropical cyclones could be regarded as deep uncertainty (Lempert et al. 2003), or ambiguity, where there is incomplete or conflicting information about the probability of different states (Gilboa 2009). Several past studies have argued that given the nature of the uncertainties in climate change, long-term adaptation problems will often be a case of decision making under deep uncertainty (Dessai et al. 2009; Lempert et al. 2003; Groves et al. 2008a; Morgan et al. 1999; Oreskes et al. 2010; Stainforth et al. 2007a,b).

There is a deep literature on the implications of ambiguity for decision making that is directly relevant to the interpretation of climate projections for adaptation and the design of scenarios to support decision making. Millner et al. 2010 summarizes the literature and applies the key arguments for the case of assessing responses to climate change. A central conclusion described by Millner et al. is the traditional approach for decision making under uncertainty, expected value analysis (or in its more generalized form, subjective expected utility (SEU) theory, Savage 1954) is not appropriate to apply under conditions of ambiguity. SEU theory takes as an input a unique subjective probability distribution (SPD) over all possible future states. For a case where there are multiple scenarios of future states and no probability 
information, SEU theory allows one to elicit expert beliefs about the likelihood of different scenarios to generate a unique SPD. Several authors have argued that in a case like this, where there is ambiguity over the likelihood of different scenarios (i.e. a secondary uncertainty in the SPD), it is not rational to ignore ambiguity and assign a single probability estimate for each future scenario (Gilboa et al. 2009, Lempert et al. 2003 and Morgan 2003). Further, Ellsberg (1961) and Slovic and Tversky (1974) demonstrate that in cases where there is ambiguity, SEU theory is not a good model of actual behavior as decision makers tend to put more weight on options that have a lower degree of ambiguity (i.e. they are ambiguity averse). The outcome of this debate has been a series of alterative decision making approaches, such as robust decision making (Lempert et al. 2003; van der Heijden, 2005), that do not rely on a unique SPD and take account of the ambiguity over future scenarios. The key input to these methods is an understanding of the range of plausible future scenarios. These types of approaches tend to emphasize 'no-regrets' options and flexible adaptation strategies, which perform well under a wide range of possible future scenarios and have been applied to adaptation planning (Lowe et al. 2009, Groves et al. 2008a and Dessai and Hulme, 2007).

From this series of arguments, we argue firstly that to best inform decision making, a priority for climate scientists and modelers is to: (i) clarify the range of possible future states of hurricane activity (as a function of time), the key drivers and nature of the potential impacts, and (ii) narrow the range of plausible future states where possible by reducing sources of uncertainty. Secondly, efforts to quantify unique SPDs of long-term hurricane activity based on models available today, will be of little value to decision makers (or potentially negative value is misused, Hall 2007) given the substantial residual (i.e. unquantifiable, secondary) uncertainties in current projections and the fact that methods are available to inform decisions without unique SPDs.

This research has suggested a number of lessons for the design of future climate modeling experiments and climate analyses to meet these needs; firstly, the importance of better understanding the role of natural cycles (and therefore, climate change) in driving variability in tropical cyclone activity and the climate of the Atlantic. We have shown how a better understanding of the role of natural cycles and climate change in past and present tropical cyclone activity is important for clarifying current and future risk levels and may allow us to eliminate some future scenarios. Linked with this, the analyses also points toward the importance of observations and of careful study of observational records in order to pinpoint early signals of changes in tropical cyclone characteristics.

For future climate modeling, we draw three conclusions: 
Firstly, there is a need for more study of the adequacy of models. There are many fundamental questions that need to be addressed: for example, does the fact that current GCMs are unable to fully represent historical co-variations of MDR SSTs and windshear shown in Section 4 suggest an inadequacy for forecasting future conditions for tropical cyclone formation and evolution? Is it sufficient for a model to represent current tropical cyclone climatology and multi-annual variability, even if there are suggestions that they are right for the wrong reasons? From such questions, one might be able to define a set of necessary, not sufficient, tests for model adequacy for a given application. Such analyses may in time enable one to exclude certain scenarios or estimate relative confidence and therefore, refine adaptation decisions.

Secondly, we have demonstrated that scientific analyses and improved modeling to give greater certainty about the sign of future changes in tropospheric large-scale vertical windshear over the Atlantic would narrow the range of uncertainty in future (wind-driven) hurricane risk for Florida; our results suggest that the sign of future wind shear changes appears to be a key determinant of the sign of future changes in risk. But clarifying the sign of future wind shear changes is not an easy task, as future windshear is dependent on many other large-scale changes, such as the latitudinal temperature gradients of the atmosphere, and changes to natural cycles like ENSO.

Thirdly, the need to explore the full range of uncertainty in future states. In the main, climate modelers have attempted to generate projections that represent a 'best guess' conditioned on a particular model structure. Recently, some studies have set out to more fully explore the range of uncertainties in future climate projections, for example: Murphy et al. 2009 sets out to generate scenarios (with probability estimates) of the UK climate to 2090 using a 'perturbed physics ensemble', which explores parameter uncertainty in the HadSM3 GCM; and Groves et al. 2008b and Dessai and Hulme, 2007 each use multiple models (GCMs and/or downscaling approaches with differing assumptions) to produce sets of scenarios of extreme rainfall over California and water supplies in the East of England, respectively. We argue that while these studies represent a significant step forward in exploring uncertainty, they still do not explore the full range of uncertainties because they are conditioned on one (or a handful of non-independent, Knutti et al. 2010) GCMs. This means that uncertainties associated with model structure are not explored. We suggest that to inform adaptation, climate experiments include analyses that leave the confines of current GCM structures and attempt to explore the range of possible outcomes, for example, using simple models or considering theoretical limits. 
There are some limitations of the current scenario set that require further study. Firstly, this study has only explored scenarios of the frequency and intensity of tropical cyclones in the Atlantic Basin. There are additional uncertainties in other characteristics of tropical cyclones (for example, their landfall frequencies and locations) that could be important to take account of if it were shown that the choices between adaptation options were also dependent on these assumptions. Secondly, this study has only explored wind-driven risks from tropical cyclones. In reality, adaptation planners will also need to consider other risks associated with tropical cyclones, such as storm surge risks and rainfall-driven damage.

\section{Summary}

This paper has put forward a set of scenarios of long-term tropical cyclone frequency and intensity for the Atlantic Basin with the aim of informing adaptation planning. These are used to generate risk scenarios using a coupled catastrophe-climate modeling approach. The scenarios suggest that wind-related hurricane losses in Florida could half or increase more than a four-fold by the end of the century due to climate change alone. We conclude that natural variability is likely to be the dominant driver of the level and volatility of wind-related risk over the coming decade; however, the superposition of climate change and natural variability means that under some scenarios we can not exclude the possibility of experiencing new extremes in risk within the decade. We also present a series of analyses to better understand the relative adequacy of the different models that underpin the scenarios and conclude that it is impossible based on current science to quantify their relative likelihood. This leads to the conclusion that planning adaptation to long-term tropical cyclone risk in the Atlantic will likely be a case of decision making under deep uncertainty. Finally, we draw specific conclusions for the needs from the science and modelling going forwards to better inform adaptation, including: a better understanding of the drivers of current variability and the role of climate change today; improved monitoring to detect early signals of change; analyses to deliver greater certainty future windshear in the Atlantic Basin; and a greater focus on exploring the full range of uncertainties in long-term projections, moving outside of the confines of current GCM structures.

\section{Acknowledgements}

We are grateful to colleagues who provided helpful discussions toward the development of this paper, including: Simon Dietz, Jan Eichner, Eberhard Faust, Kerry Emanuel, Patricia Grossi, Iris Grossmann, Greg Holland, Thomas Knutson, Howard Kunreuther, Erwann Michel-Kerjan, Robert Muir-Wood, Leonard Smith, David Stainforth, Pantea Vaziri, Gabriel Vecchi and Michael Young. We are particularly grateful to Risk Management Solutions 
(RMS) Inc. for sharing loss information for Florida and to Professor Emanuel for supplying projections from E2008. Drs Niehörster and Ranger's research was supported by the Centre for Climate Change Economics and Policy, funded by the Economic and Social Research Council and Munich Re.

\section{References}

Applied Research Associates Inc. (2008) 2008 Florida Residential Wind Loss Mitigation Study. Prepared for the Florida Office of Insurance Regulation. ARA Final Report 18401, version.1.11.

Bender, M.A., Knutson T.R., Tuleya R.E., Sirutis J.J., Vecchi G.A., Garner S.T. and Held I.M. (2010) Modeled Impact of Anthropogenic Warming on the Frequency of Intense Atlantic Hurricanes. Science, 327, 454-458.

Bengtsson, L., Hodges, K.I., Esch, M., Keenlyside, N., Kornblueh, L., Luo, J.J. and Yamagata, T. (2007) How may tropical cyclones change in a warmer climate? Tellus, 59A (4), 539-560.

Casman, E.A., Morgan, M.G. and Dowlatabadi, H. (1999) Mixed Levels of Uncertainty in Complex Policy Models. Risk Anal., 19 (1), 33-42

Crompton, R.P., Pielke, R.A. Jr. and McAneney, K.J. (2011) Emergence timescales for detection of anthropogenic climate change in US tropical cyclone loss data. Environ. Res. Lett., 6, 014003, doi:10.1088/1748-9326/6/1/014003

Cox, P. and Stephenson, D. (2007) A Changing Climate for Prediction. Science, 317, 207-208, doi:10.1126/science. 1145956

Dessai, S. and Hulme, M. (2007) Assessing the robustness of adaptation decisions to climate change uncertainties: A case study on water resources management in the East of England. Global Environ. Chang., 17, 59-72.

Dessai, S., Hulme, M., Lempert, R. and Pielke R. Jr. (2009) Climate prediction: A limit to adaptation? In Adapting to Climate Change: Thresholds, Values, Governance. Cambridge University Press, Cambridge.

Emanuel, K. (2008) The Hurricane-Climate Connection. B. Am. Meteorol. Soc. 89 (5) DOI: 10.1175/BAMS-89-5-Emanuel

Emanuel, K., Sundararajan, R. and Williams, J. (2008) Hurricanes and global warming: results from downscaling IPCC AR4 simulations. B. Am. Meteorol. Soc. 89, 347-367

Emanuel, K. (2005) Increasing destructiveness of tropical cyclones over the past 30 years. Nature, 436, 686-688.

Emanuel, K. (1987) The dependence of hurricane intensity on climate. Nature, 362, 483-485.

Ellsberg, D. (1961) Risk, ambiguity and the Savage axioms. Q. J. Econ., 75, 643-69.

Elsner, J. (2006) Evidence in support of the climate change-Atlantic hurricane Hypothesis. Geophys. Res. Lett., 33, L16705.

Gilboa, I. (2009) Theory of Decision under Uncertainty (Econometric Society Monographs). Cambridge University Press, New York.

Gilboa, I., Postlewaite, A. and Schmeidler, D. (2009) Is it always rational to satisfy savage's axioms? Econ. Philos., 25, 285-296.

Gillett, N.P., Stott, P.A. and Santer, B.D. (2008) Attribution of cyclogenesis region sea surface temperature change to anthropogenic influence. Geophys. Res. Lett., 35, L09707, doi: 10.1029/2008GL033670.

Goldenberg, S.B., Landsea, C.W., Mestas-Nuñez, A.M. and Gray, W.M. (2001) The Recent Increase in Atlantic Hurricane Activity: Causes and Implications. Science, 293, 474-479.

Grossi, P and Kunreuther, H. [eds.] (2005) Catastrophe Modeling: A new approach to managing risk, Huebner International Series on Risk, Insurance and Economic Security, Springer, New York 
Groves, D.G. and Lempert, R.J. (2006) A new analytic method for finding policy-relevant scenarios. Global Environ. Chang., 17, 73-85.

Groves, D.G., Lempert, R.J., Knopman, D. and Berry, S.H. (2008a) Preparing for an Uncertain Future Climate in the Inland Empire: Identifying Robust Water-Management Strategies, RAND Corporation, Santa Monica

Groves, D.G., Yates, D. and Tebaldi, C. (2008b) Developing and applying uncertain global climate change projections for regional water management planning. Water Resour. Res., 44 (W12413), Doi: 10.1029/2008WR006964.

Hall, J.W. (2007) Probabilistic climate scenarios may misrepresent uncertainty and lead to bad adaptation decisions. Hydrol. Process., 21(8), 1127-1129.

Hallegatte, S. (2009) Strategies to adapt to an uncertain climate change. Global Environ. Chang., 19, 2040-2047. doi:10.1016/j.gloenvcha.2008.12.003

Hawkins, E. and Sutton, R. (2009) The potential to narrow uncertainty in regional climate predictions. B. Am. Meteorol. Soc. Doi:10.1175/2009BAMS2607.1

Holland, G.J. and Webster, P.J. (2007) Heightened Tropical Cyclone Activity in the North Atlantic: Natural Variability or Climate Trend? Phil. Trans. R. Soc. A, 365 (1860), 2695-2716, doi: 10.1098/rsta.2007.2083

Hoyos, C. D., Agudelo P. A., Webster P. J. and Curry J. A. (2006) Deconvolution of the Factors Contributing to the Increase in Global Hurricane Intensity. Science, 312 (5770), 94-97.

Intergovernmental Panel on Climate Change (2005) Guidance Notes for Lead Authors of the IPCC Fourth Assessment Report on Addressing Uncertainties. https://www.ipccwg1.unibe.ch/publications/supportingmaterial/uncertainty-guidance-note.pdf

Jones, R.N. (2000) Managing uncertainty in climate change projections: Issues for impact assessment. Climatic Change, 45, 403-419, Doi: 10.1023/A:1005551626280

Knutson T.R., McBride J.L., Chan J., Emanuel K., Holland G., Landsea C., Held I., Kossin J.P., Srivastava A.K. and Sugi M. (2010) Tropical cyclones and climate change. Nature Geosci., 3, 157-163.

Knutti, R., Abramowitz, G., Collins, M., Eyring, V., Glecker, P.J., Hewitson, B. and Mearns, L. (2010) Good Practice Guidance Paper on Assessing and Combining Multi Model Climate Projections. Report of the IPCC Expert Meeting on Assessing and Combining Multi Model Climate Projections, 25-27 January 2010. [Stocker, T., Dahe, Q., Plattner, G.-K., Tignor, M. \& Midgley, P. eds.], http://www.ipcc.ch/pdf/supporting-material/IPCC_EM_MME_GoodPracticeGuidancePaper.pdf

Landsea, C. W., Anderson, C., Charles, N., Clark, G., Dunion, J., Partagas, J., Hungerford, P., Neumann, C. and Zimmer, M. (2004) The Atlantic hurricane database re-analysis project: Documentation for the 1851-1910 alterations and additions to the HURDAT database. Hurricanes and Typhoons: Past, Present and Future, [R. J. Murnane and K.-B. Liu, Eds.] pp. 177-221. Columbia University Press, New York.

Lempert, R.J., Popper, S.W. and Bankes, S.C. (2003) Shaping the Next One Hundred Years: New Methods for Quantitative, Long-Term Policy Analysis, RAND, Santa Monica.

Lowe, J. A., Howard, T. P., Pardaens, A., Tinker, J., Holt, J., Wakelin, S., Milne, G., Leake, J., Wolf, J., Horsburgh, K., Reeder, T., Jenkins, G., Ridley, J., Dye, S. and Bradley, S. (2009) Thames Estuary 2100 case study, Chapter 7 in: UK Climate Projections science report: Marine and coastal projections. Met Office Hadley Centre, Exeter.

Nakicenovic, N. and R. Swart (eds.) (2000) Special Report on Emissions Scenarios. A Special Report of Working Group III of the Intergovernmental Panel on Climate Change. Cambridge University Press, Cambridge and New York.

Mann, M. and Emanuel, K. (2006) Atlantic hurricane trends linked to climate change. Eos, 87, 233241.

Maraun, D., Wetterhall, F., Ireson, A. M., Chandler, R. E., Kendon, E. J., Widmann, M., Brienen, S.,Rust, H. W., Sauter, T., Themeß1, M., Venema, V. K. C., Chun, K. P., Goodess, C. M., Jones, R. G., Onof, C., Vrac, M. and Thiele-Eich, I. (2010) Precipitation downscaling under climate change: Recent 
developments to bridge the gap between dynamical models and the end user. Rev. Geophys., 48, doi:10.1029/2009RG000314.

McAvaney B.J., Covey C., Joussaume S., Kattsov V., Kitoh A., Ogana W., Pitman A.J., Weaver A.J., Wood R.A., Zhao Z.-C. and co-authors (2001) Model Evaluation. In Climate Change 2001:

Contribution of Working Group I to the Third Assessment Report of the Intergovernmental Panel on Climate Change. Cambridge University Press, Cambridge and New York.

Millner, A., Dietz, S. and Heal, G. (2010) Ambiguity and climate policy. Working paper of the Centre for Climate Change Economics and Policy (No. 28).

Morgan, M.G. (2003) Characterizing and Dealing with Uncertainty: Insights from the Integrated Assessment of Climate Change. Integr. Assessment, 4 (1). 46-55.

Morgan, M.G., Kandlikar, M., Risbey, J. and Dowlatabadi, H. (1999) Why conventional tools for policy analysis are often inadequate for problems of global change: an editorial essay. Climatic Change. 41, 271-281.

Morgan, M.G. and Henrion, M. (1990) Uncertainty: A Guide to Dealing with Uncertainty in Quantitative Risk and Policy Analysis. Cambridge University Press, Cambridge and New York.

Murphy, J.M., Sexton, D.M.H., Jenkins, G.J., Boorman, P.M., Booth, B.B.B., Brown, C.C., Clark, R.T., Collins, M., Harris, G.R., Kendon, E.J., Betts, R.A., Brown, S.J., Howard, T. P., Humphrey, K. A., McCarthy, M. P., McDonald, R. E., Stephens, A., Wallace, C., Warren, R., Wilby, R. and Wood, R. A. (2009) UK Climate Projections Science Report: Climate change projections. Met Office Hadley Centre, Exeter.

Neumayer, E. and Barthel, F. (2010) Normalizing economic loss from natural disasters: A global analysis. Global Environ. Chang.. 21, 13-24. doi:10.1016/j.gloenvcha.2010.10.004

Oreskes, N., Stainforth, D. and Smith, L. (2010) Adaptation to Global Warming: Do Climate Models Tell Us What We Need to Know? Philos. Sci., 77 (5), 1012-1028.

Parson, E.A. (2008) Useful global change scenarios: current issues and challenges. Environ. Res. Lett., 3, 045016, doi: 10.1088/1748-9326/3/4/045016.

Pielke Jr., R.A. and Landsea, C.W. (1998) Normalized hurricane damages in the United States: 19251995. Weather Forecast. 621-631 (September).

Randall, D.A., Wood R.A., Bony S., Colman R., Fichefet T., Fyfe J., Kattsov V., Pitman A., Shukla J., Srinivasan J., Stouffer R.J., Sumi A. and Taylor K.E. (2007) Climate Models and Their Evaluation. In: Climate Change 2007: The Physical Science Basis. Contribution of Working Group I to the Fourth Assessment Report of the Intergovernmental Panel on Climate Change [Solomon, S., D. Qin, M. Manning, Z. Chen, M. Marquis, K.B. Averyt, M.Tignor and H.L. Miller (eds.)]. Cambridge University Press, Cambridge and New York.

Ranger, N., Millner, A., Dietz, S., Fankhauser, S., Lopez, A. and Ruta, G. (2010) Adaptation in the UK: a decision making process. Policy briefing of the Grantham Research Institute on Climate Change and the Environment, London School of Economics and Political Science, and the Centre for Climate Change Economics and Policy. http://www2.1se.ac.uk/GranthamInstitute/publications/Policy/briefs.aspx

Roe, G.H. and Baker, M.B. (2007) Why Is Climate Sensitivity So Unpredictable. Science, 318, 629632, doi: $10.1126 /$ science. 1144735 .

Risk Management Solutions (RMS) (2010) Study of Florida's Windstorm Mitigation Credits: Assessing the Impact on the Florida Insurance Market. http://www.rms.com/publications/RMS_Study_of_Floridas_Windstorm_Mitigation_Credits.pdf

Santer B. D., Wigley T. M. L., Gleckler P. J., Bonfils C., Wehner M. F., AchutaRao K., Barnett T. P., Boyle J. S., Bruggemann W., Fiorino M., Gillett N., Hansen J. E., Jones P. D., Klein S. A., Meehl G. A., Raper S. C. B.,Reynolds R. W., Taylor K. E., \& Washington W. M. (2006) Forced and unforced ocean temperature changes in Atlantic and Pacific tropical cyclogenesis regions. P Natl. Acad. Sci. USA, 103, 38, 13905-13910.

Saunders, M.A. and Lea, A.S. (2008) Large contribution of sea surface warming to recent increase in Atlantic hurricane activity. Nature 451, 557-560. 
Savage, L.J. (1954) Foundations of Statistics, Wiley, New York.

Slovic, P and Tversky A. (1974) Who accepts Savage's axiom? Behav. Sci., 19(6), 368-373.

Smith, D.M., Eade, R., Dunstone, N.J., Fereday, D., Murphy, J.M., Pohlmann, H. and Scaife, A.A. (2010) Skilful multi-year predictions of Atlantic hurricane frequency. Nature geosci., Doi:10.1038/NGEO1004

Stainforth, D., Downing, T.E., Washington, R., Lopez, A. and New, M. (2007a) Issues in the interpretation of climate model ensembles to inform decisions. Philos. T. Roy. Soc. A, 365, 2163-2177.

Stainforth, D, Allen, M.R., Tredger, E.R. and Smith, L.A. (2007b) Confidence, uncertainty and decision-support relevance in climate predictions. Philos. T. Roy. Soc. A, 365, 2145-2161.

Trenberth, K.E. and Shea, D.J. (2006) Atlantic hurricanes and natural variability in 2005. Geophys. Res. Lett., 33, L12704, doi:10.1029/2006GL026894.

Trenberth, K. (2005) Uncertainty in hurricanes and global warming. Science, 308, 1753-1754.

Uppala, S. and coauthors (2005) The ERA-40 re-analysis. Quart. J. R. Meteorol. Soc., 131, 2961-3012. US Census Bureau, http://www.census.gov/

Van der Heijden, K. (2005) Scenarios: the art of strategic conversation (second edition). John Wiley \& Sons Ltd. Chichester.

Vecchi, G.A., Swanson, K.L. and Soden, B.J. (2008) Whither hurricane activity? Science, 322, 687689, doi:10.1126/science.1164396.

Vecchi, G. and Soden B. (2007a) Effect of remote sea surface temperature change on tropical cyclone potential intensity. Nature, 450, 1066-1071, doi: 10.1038/nature06423.

Vecchi, G.J. and Soden, B.A. (2007b) Increased tropical Atlantic wind shear in model projections of global warming. Geophys. Res. Lett., 34, L08702, doi:10.1029/2006GL028905.

Zickfeld, K., Morgan, M.G., Frame, D.J. and Keith, D.W. (2010) Expert judgements about transient climate response to alternative future trajectories of radiative forcing. P Natl. Acad. Sci. USA, 107 (28), 12451-12456. 